\title{
Impact of marked weight loss induced by bariatric surgery on bone mineral density and remodeling
}

F.A. Pereira ${ }^{1}$,

J.A.S. de Castro ${ }^{1}$,

J.E. dos Santos ${ }^{2}$,

M.C. Foss ${ }^{1}$ and F.J.A Paula ${ }^{1}$
${ }^{1}$ Divisão de Endocrinologia e Metabolismo, ${ }^{2}$ Divisão de Nutrologia, Departamento de Clínica Médica, Faculdade de Medicina de Ribeirão Preto, Universidade de São Paulo, Ribeirão Preto, SP, Brasil

\section{Correspondence \\ F.J.A. de Paula \\ Departamento de Clínica Médica FMRP, USP \\ 14049-900 Ribeirão Preto, SP Brasil \\ Fax: +55-16-3633-6695 \\ E-mail: fjpaula@fmrp.usp.br}

Research supported by FAEPA.

Publication supported by FAPESP.

Received April 11, 2006 Accepted December 18, 2006

\begin{abstract}
Data about the impact of bariatric surgery (BS) and subsequent weight loss on bone are limited. The objective of the present study was to determine bone mineral density (BMD), bone remodeling metabolites and hormones that influence bone trophism in premenopausal women submitted to BS 9.8 months, on average, before the study (OGg, $\mathrm{N}=$ 16). The data were compared to those obtained for women of normal weight ( $\mathrm{CG}, \mathrm{N}=11)$ and for obese women (OG, $\mathrm{N}=12$ ). Eight patients in each group were monitored for one year, with the determination of BMD, of serum calcium, phosphorus, magnesium, parathyroid hormone, 25-hydroxyvitamin D, insulin-like growth factor-I (IGF-I) and osteocalcin, and of urinary calcium and deoxypyridinoline. The biochemical determinations were repeated every three months in the longitudinal study and BMD was measured at the end of the study. Parathyroid hormone levels were similar in the three groups. IGF-I levels $(\mathrm{CG}=332 \pm 62$ vs OG $=230 \pm 37$ vs $\mathrm{OGg}=128 \pm 19 \mathrm{ng} /$ $\mathrm{mL}$ ) were significantly lower in the operated patients compared to the non-operated obese women. Only OGg patients presented a significant fall in BMD of $6.2 \%$ at L1-L4, of $10.2 \%$ in the femoral neck, and of $5.1 \%$ in the forearm. These results suggest that the weight loss induced by BS is associated with a significant loss of bone mass even at sites that are not influenced by weight overload, with hormonal factors such as IGF-I being associated with this process.
\end{abstract}

Key words

- Osteoporosis

- Obesity

- Bone mineral density

- Bone turnover

- Bariatric surgery

\section{Introduction}

Obesity is associated with a long list of co-morbidities ranging from simple health problems such as osteoarticular disorders and varices to severe chronic diseases such as diabetes mellitus, arterial hypertension and cardiovascular disease $(1,2)$. On the other hand, obesity has a beneficial effect on the development and maintenance of bone mass $(3,4)$.

A great increase in the prevalence of morbid obesity has been observed over the last decades (1). In this condition there is a marked impairment of quality of life and a significant reduction of life expectancy, and it has not been clearly demonstrated if the benefits of obesity regarding bone mass are 
preserved at this level of the condition. As a consequence, there has been great interest in the development of efficient therapeutic measures for morbid obesity. Unfortunately, the various clinical treatments proposed that involve changes of habits and the use of several classes of medications have yielded frustrating results on a long-term basis (3). This is largely due to the slow process of weight loss and to the need for strong involvement and effort on the part of the patient that should last throughout life. The need to develop therapeutic options whose efficacy is less dependent on the patient's will regarding a change in habits has favored the use of gastric reduction surgery as a frequent option (3).

The rationale behind this treatment, as well as others, should be solving the patient's complaints, reducing the life risks and not producing undesirable side effects. Regarding bariatric surgery, previous results have shown higher short- and medium-term success rates than other options for the induction of weight loss $(3,4)$. There still is the need to determine the long-term success of this treatment regarding the maintenance of weight, the improvement of quality of life and the increase in life expectancy. It is also important to determine if the loss of bone mass may represent an important side effect of this treatment.

The main mechanism responsible for the loss of bone mass after bariatric surgery has not been identified, but the following factors may be involved: the weight loss itself with loss of fat and lean mass, nutritional disorders, hormonal changes (steroids, growth hormone, growth factors, and insulin), and disorders of mineral metabolism $(5,6)$.

The objective of the present study was to determine bone mineral density (BMD) and biochemical parameters of bone remodeling in obese individuals submitted to bariatric surgery at least 3 months before the study. A subgroup of patients was followed up for biochemical re-evaluations at three-month intervals and annual BMD re-evaluation. In addition, the biochemical parameters of mineral metabolism (calcium, phosphorus, magnesium, parathyroid hormone (PTHi), and 25-hydroxyvitamin D) and the levels of insulin-like growth factor I (IGF-I) of these patients were also measured.

\section{Material and Methods}

The study was conducted on 39 women, 11 of them non-obese (control group, CG), 12 of them obese (OG) and 16 of them obese patients submitted to gastroplasty with bandaging and Roux-en-Y bypass (OGg) (crosssectional study). A subset of 8 individuals of each group agreed to be followed prospectively and were assessed at 3-month intervals for 1 year (prospective study). The OGg consisted of all patients submitted to gastroplasty with bandaging and Roux-en-Y bypass who were being followed at the Outpatient Clinic of Nutrology of the University Medical Center, School of Medicine of Ribeirão Preto, University of São Paulo. The surgical procedure resulted in a $20-\mathrm{mL}$ isolated gastric pouch, a stapled end-side gastrojejunostomy, a 100-cm Roux-limb, a 3050-cm biliopancreatic limb, and a stapled end-side enteroenterostomy. Therefore, the stomach was divided into an upper small pouch and a large lower segment followed by an anastomosis of a Roux-en-Y intestinal configuration with the proximal gastric pouch, resulting in the intended gastric bypass. OGg women received an oral daily polyvitamin supplement containing $400 \mathrm{IU}$ cholecalciferol and $250 \mathrm{mg}$ calcium carbonate (Materna, Wyeth, São Paulo, SP, Brazil). OG patients were also followed at the Nutrology Outpatient Clinic of the University Medical Center, School of Medicine of Ribeirão Preto, University of São Paulo. The patients and controls enrolled in the study were selected on the basis of clinical history and laboratory tests. Individuals with a personal or family history of osteometabolic 
diseases, taking medications that affect mineral metabolism (estrogens, anticonvulsants, glucocorticoids, and diuretics) and with a history of alcoholism or smoking were excluded. No patient was in the postmenopausal phase and all had regular menstrual cycles. The study was evaluated and approved by the Ethics Committee of the University Hospital, Faculty of Medicine of Ribeirão Preto, USP, and the patients gave written informed consent to participate in the study.

All subjects in the control group had a body mass index (BMI) below $30 \mathrm{~kg} / \mathrm{m}^{2}$ (range: 23.7 to $29.6 \mathrm{~kg} / \mathrm{m}^{2}$ ) and in the obese group the BMI was above $40 \mathrm{~kg} / \mathrm{m}^{2}$ (range: 40.3 to $67.8 \mathrm{~kg} / \mathrm{m}^{2}$ ). On the occasion of the first evaluation of the operated patients, carried out on average $9.8 \pm 1.9$ months after surgery, the weight was significantly lower than that of obese patients not submitted to surgery, with BMI ranging from 22.3 to 44.3 $\mathrm{kg} / \mathrm{m}^{2}$. However, before surgery, the weight was similar in the two groups $(\mathrm{OG}=122.4 \pm$ $7 v s \mathrm{OGg}=130.5 \pm 4.4 \mathrm{~kg}$ ). There were no significant differences in age or height between groups in either study. The physical characteristics of the groups in the crosssectional study are presented in Table 1 . The mean age of the groups in the longitudinal study was: $\mathrm{CG}=39.8 \pm 3.8$ vs $\mathrm{OG}=34.1 \pm$ $3.0 v s \mathrm{OGg}=39.5 \pm 3.3$ years, and the mean height was $\mathrm{CG}=1.59 \pm 0.02$ vs $\mathrm{OG}=1.58 \pm$ 0.02 vs $\mathrm{OGg}=1.60 \pm 0.01 \mathrm{~m}$.

The groups were formed simultaneously in order to prevent seasonal influence on serum levels of 25-hydroxyvitamin D. In the prospective study, blood and urine samples were collected at 3-month intervals for one year, for biochemical determinations of mineral metabolism and bone remodeling parameters and the measurement of BMD was repeated after one year.

Blood samples were collected in the morning after a 10- to 14-h fast, centrifuged in a refrigerated centrifuge and used for biochemical determinations (calcium, cal- cium ion, phosphorus, alkaline phosphatase, magnesium, and albumin) and measurements of PTHi, IGF-I, 25-hydroxyvitamin D, and osteocalcin. On the same day, the patients brought 24-h urine for the determination of calcium and creatinine corresponding to the preceding day and collected a sample of the second morning urine for the determination of deoxypyridinoline and creatinine. The biochemical determinations were performed on the day of collection, whereas the samples to be used for the determination of the other serum and urine parameters were stored at $-70^{\circ} \mathrm{C}$ until the day for use.

Total calcium, inorganic phosphorus, alkaline phosphatase, and serum albumin were determined with an automatic biochemical analyzer (Dimension RXL, Dade-Behring, Atlanta, GA, USA). Blood for the determination of serum calcium ion was collected under anaerobic conditions and immediately processed with an analyzer equipped with a selective electrode (Stat Profile Plus 9 Analyzer, Nova Biomedical, Waltham, MS, USA).

PTHi was determined by chemiluminescence (Diagnostic Products Corporation, Los Angeles, CA, USA). The intra- and interassay coefficients of variation (CV) were 4.0 and $4.4 \%$, respectively. 25-Hydroxyvitamin $\mathrm{D}$ was measured by radioimmunoassay (Nichols Institute, San Juan Capistrano, CA, USA) in a single assay, with a CV of $7.2 \%$. IGF-I was determined by an immunoradiometric method (Diagnostic Systems Laboratories, Webster, TX, USA), with intra- and interassay CV of 3.5 and $5.3 \%$, respectively. Serum levels of osteocalcin were determined by an immunoradiometric method (DSL7600, IRMA, Webster, TX, USA), with intra- and interassay errors of 5.3 and 8.0\%, respectively. The urinary levels of deoxypyridinoline were determined by enzyme immunoassay (Metra Biosystems, Mountain View, CA, USA), with an intra-assay error of $2.0 \%$, and the result is reported in relation to the rate of urinary excretion of creatinine.

Bone mass was measured by double en- 
ergy X-ray absorptiometry using a model 4500W Hologic apparatus (Hologic 4500W, Waltham, MA, USA). The sites evaluated were L1-L4, the femoral neck, and the distal $1 / 3$ of the forearm, with respective $\mathrm{CV}$ of $2.1,2.3$, and $1.7 \%$. The $\mathrm{CV}$ was estimated by the method of Gluier et al. (7): $\mathrm{CVt}=\left(\mathrm{S}_{\mathrm{t}} / \sum \mathrm{Xj} /\right.$ m) $\mathrm{x} 100$, where $\mathrm{Xj}$ represents the means of five exams preformed in 5 patients, $m$ represents the number of patients (5) and $\mathrm{S}_{\mathrm{t}}$ represents the standard deviation $\left(S_{t}=\sqrt{ } \sum S^{2} / m\right)$ (7). In the individuals of the obese group, only the forearm site was evaluated in view of the limitation of the equipment in supporting a weight of more than $120 \mathrm{~kg}$. The individuals in the longitudinal study were evaluated for bone mass at the beginning of the study and at the end of one year.

Data were analyzed statistically with the GraphPad Prism software, version 3.0 for Windows, 1999 (GraphPad Prism, San Diego, CA, USA) and submitted to the following tests: a) ANOVA followed by the Tukey test for multiple comparisons for the numerical variables with normal distribution, b) the paired Student $t$-test for the data of the same group and the unpaired $t$-test for the data of different groups regarding bone densitometry, and c) the Pearson correlation coefficient for the calculation of correlation between parametric variables. The results are reported as means \pm SEM, with the level of significance set at $5 \%(\mathrm{P}<0.05)$.

Table 1. Characteristics of the individuals of the control group (CG), obese group (OG) and obese group submitted to bariatric surgery $(\mathrm{OGg})$ determined in the crosssectional study.

\begin{tabular}{lccc}
\hline & $\mathrm{CG}(\mathrm{N}=11)$ & $\mathrm{OG}(\mathrm{N}=12)$ & $\mathrm{OGg}(\mathrm{N}=16)$ \\
\hline Age (years) & $37.2 \pm 3.09$ & $32.4 \pm 0.01$ & $37.8 \pm 1.70$ \\
Height $(\mathrm{m})$ & $1.58 \pm 0.01$ & $1.59 \pm 0.01$ & $1.64 \pm 0.01$ \\
Weight $(\mathrm{kg})^{*, * *}$ & $67.7 \pm 2.20$ & $122.4 \pm 7.0$ & $89.6 \pm 4.1$ \\
BMI $\left(\mathrm{kg} / \mathrm{m}^{2}\right)^{*, * * *}$ & $26.7 \pm 0.70$ & $47.7 \pm 2.50$ & $33.4 \pm 1.60$ \\
Time after surgery (months) & - & - & $9.8 \pm 1.90$ \\
\hline
\end{tabular}

Data are reported as mean $\pm \mathrm{SEM}$. BMI $=$ body mass index.

${ }^{\star} \mathrm{P}<0.001$ for $\mathrm{CG}$ vs $\mathrm{OG}$; ${ }^{* \star} \mathrm{P}<0.001$ for $\mathrm{OG}$ vs $\mathrm{OGg}$; ${ }^{* \star *} \mathrm{P}<0.01$ for $\mathrm{CG}$ vs $\mathrm{OGg}$ (ANOVA followed by the multiple comparisons Tukey test for the numerical variables with normal distribution).

\section{Results}

In the cross-sectional study, the individuals submitted to surgery were evaluated $9.8 \pm 1.9$ months after gastroplasty. During this period the patients had lost about $30.6 \pm$ $3.3 \mathrm{~kg}$ and their weight was significantly lower than that of the obese group $(\mathrm{P}<$ $0.001)$, but still higher than that of the control group $(\mathrm{P}<0.01$; Table 1$)$. There was no significant difference in calcium, $\mathrm{Ca}^{2+}, \mathrm{Pi}$, alkaline phosphatase, albumin, or $\mathrm{Mg}$. Serum levels of PTHi $(\mathrm{CG}=29.5 \pm 3.6$ vs $\mathrm{OG}$ $=39.4 \pm 8.9 v s \mathrm{OGg}=33.7 \pm 2.5 \mathrm{pg} / \mathrm{mL})$ and 25-hydroxyvitamin $\mathrm{D}(\mathrm{CG}=47.9 \pm 2.2$ vs $\mathrm{OG}=46.0 \pm 1.6 v s \mathrm{OGg}=49.6 \pm 1.9 \mathrm{ng} / \mathrm{mL}$ ) were similar in the three groups. Calciuria was significantly lower in the OGg than in the other two groups $(\mathrm{CG}=177 \pm 11 v$ s $\mathrm{OG}$ $=211 \pm 15$ vs $\mathrm{OGg}=77 \pm 6 \mathrm{mg} / 24 \mathrm{~h} ; \mathrm{P}<$ $0.001)$ and was correlated with weight loss $(\mathrm{P}<0.006, \mathrm{r}=0.647)$ and time since surgery $(\mathrm{P}<0.0001, r=0.85)$.

The control group had IGF-I levels similar to those of the non-operated obese group but significantly higher than those of the group submitted to bariatric surgery $(\mathrm{CG}=$ $332 \pm 62$ vs $\mathrm{OG}=230 \pm 36.9$ vs $\mathrm{OGg}=128$ $\pm 19.4 \mathrm{ng} / \mathrm{mL} ; \mathrm{P}<0.01)$. The non-operated obese group $(\mathrm{OG})$ had significantly lower osteocalcin levels than the control group ( $\mathrm{P}$ $<0.01$ ), but the levels of osteocalcin were not different between $\mathrm{OG}$ and $\mathrm{OGg}(\mathrm{CG}=$ $41.1 \pm 7.8 v s \mathrm{OG}=21.2 \pm 3.2 v s \mathrm{OGg}=32.4$ $\pm 4.4 \mathrm{ng} / \mathrm{mL}$ ). Urinary deoxypyridinoline excretion was significantly higher in the group submitted to bariatric surgery than in the other two groups $(\mathrm{CG}=5.4 \pm 1.3 v s \mathrm{OG}$ $=6.9 \pm 1.7 v s \mathrm{OGg}=23.0 \pm 3.6 \mathrm{nmol} / \mathrm{mmol}$ creatinine; $\mathrm{P}<0.001)$. There were no significant differences in urinary creatinine levels between groups $(\mathrm{CG}=14.3 \pm 0.2 \mathrm{vs} \mathrm{OG}$ $=17.0 \pm 1.9$ vs $\mathrm{OGg}=13.4 \pm 1.3 \mathrm{mmol} / \mathrm{L}$ ).

The BMD values of OGg patients were significantly higher than those of the control group at the L1-L4 site $(\mathrm{CG}=0.955 \pm 0.03 v \mathrm{~s}$ $\left.\mathrm{OGg}=1.104 \pm 0.03 \mathrm{~g} / \mathrm{cm}^{2} ; \mathrm{P}<0.005\right)$ but 
were similar to control at the femoral neck level $(\mathrm{CG}=0.886 \pm 0.02$ vs $\mathrm{OGg}=0.821 \pm$ $0.04 \mathrm{~g} / \mathrm{cm}^{2}$ ). BMD values in the distal $1 / 3$ of the radius were similar for $\mathrm{CG}$ and $\mathrm{OG}$, but the values of OGg were significantly higher than those of $\mathrm{OG}(\mathrm{CG}=0.737 \pm 0.03$ vs $\mathrm{OG}$ $=0.676 \pm 0.01$ vs $\mathrm{OGg}=0.836 \pm 0.04 \mathrm{~g} / \mathrm{cm}^{2}$; $\mathrm{P}<0.01 \mathrm{OG}$ vs OGg).

Among the individuals who participated in the longitudinal study, only those submitted to gastroplasty showed a significant variation in weight throughout the study, i.e., 11.8 $\mathrm{kg}$ or $13.4 \%$ (Table 2). In the first evaluation, these individuals had been submitted to gastroplasty about $12.4 \pm 3.2$ months before and had already lost $34.1 \pm 4.9 \%$ of their preoperative weight. The three groups showed no significant variation in calcium, calcium ion, phosphorus, alkaline phosphatase, albumin, or magnesium levels throughout the study, with no significant difference among them at any time point.
The initial calciuria of the control group $(184 \pm 6 \mathrm{mg} / 24 \mathrm{~h})$ and obese group $(225 \pm 29$ $\mathrm{mg} / 24 \mathrm{~h}$ ) was significantly higher than that of the group submitted to bariatric surgery ( $84 \pm 9 \mathrm{mg} / 24 \mathrm{~h}$ ), although the group submitted to bariatric surgery presented an increase in urinary calcium excretion along the investigation, with the following values being observed at the end of the study: $\mathrm{CG}=192 \pm$ $5 v s \mathrm{OG}=195 \pm 16$ vs $\mathrm{OGg}=157 \pm 11 \mathrm{mg} /$ $24 \mathrm{~h}$.

Serum PTHi levels remained relatively stable in the three groups throughout the study, with no significant differences among them (Table 2). Basal 25-hydroxyvitamin D levels were significantly higher in the obese individuals submitted to bariatric surgery than in the other two groups, but became similar starting from the second collection (Table 2). There was no significant difference in IGF-I levels between CG and OG throughout the study (for example, at first

Table 2. Clinical and laboratory characteristics of the individuals of the control group (CG), obese group (OG) and obese group submitted to bariatric surgery $(\mathrm{OGg}) 9.8$ months, on average, before the study and assessed at 3-month intervals for a period of one year.

\begin{tabular}{|c|c|c|c|c|c|c|c|c|c|}
\hline & $\begin{array}{c}\text { Weight } \\
(\mathrm{kg})^{*, \star *, \star * *, \#}\end{array}$ & $\% \Delta$ Weight & $\begin{array}{c}\text { BMI } \\
\left(\mathrm{kg} / \mathrm{m}^{2}\right)^{\star, \star * *,+, \#}\end{array}$ & $\begin{array}{c}\text { TAS } \\
\text { (months) }\end{array}$ & $\begin{array}{c}\text { PTHi } \\
(\mathrm{pg} / \mathrm{mL})\end{array}$ & $\begin{array}{c}\text { 25-OH-D } \\
(\mathrm{ng} / \mathrm{mL})^{+,++}\end{array}$ & $\begin{array}{c}\text { IGF-I } \\
(\mathrm{ng} / \mathrm{mL})^{++, * \star \star *}\end{array}$ & $\begin{array}{c}\text { Oc } \\
(\mathrm{ng} / \mathrm{mL})^{+++}\end{array}$ & $\begin{array}{l}\text { DPD (nmol/ } \\
\mathrm{mmol})^{\star * * \star \star * * *}\end{array}$ \\
\hline \multicolumn{10}{|l|}{ CG } \\
\hline $1 \mathrm{st}$ & $68.6 \pm 2.5$ & - & $26.9 \pm 0.7$ & - & $30.3 \pm 4.8$ & $45.5 \pm 2.7$ & $255.6 \pm 52.1$ & $40.0 \pm 10.6$ & $5.2 \pm 2.3$ \\
\hline 2nd & $68.6 \pm 2.5$ & - & $26.9 \pm 0.7$ & - & $35.1 \pm 7.6$ & $50.0 \pm 2.1$ & $238.3 \pm 48.9$ & $37.7 \pm 10.8$ & $5.6 \pm 1.8$ \\
\hline $3 r d$ & $68.7 \pm 2.5$ & - & $26.9 \pm 0.7$ & - & $27.2 \pm 3.8$ & $48.6 \pm 2.6$ & $269.1 \pm 56.3$ & $34.1 \pm 6.5$ & $5.9 \pm 1.9$ \\
\hline 4th & $68.7 \pm 2.4$ & - & $26.8 \pm 0.7$ & - & $35.9 \pm 5.6$ & $53.8 \pm 1.3$ & $233.0 \pm 60.7$ & $32.3 \pm 8.7$ & $5.9 \pm 1.9$ \\
\hline 5 th & $68.7 \pm 2.4$ & - & $26.8 \pm 0.7$ & - & $30.8 \pm 5.5$ & $50.4 \pm 1.4$ & $259.3 \pm 61.8$ & $30.7 \pm 6.5$ & $5.6 \pm 1.9$ \\
\hline \multicolumn{10}{|l|}{ OG } \\
\hline $1 \mathrm{st}$ & $117.5 \pm 6.2$ & - & $46.4 \pm 2.4$ & - & $31.4 \pm 8.7$ & $47.1 \pm 2.0$ & $184.9 \pm 35.6$ & $17.8 \pm 3.0$ & $6.4 \pm 2.2$ \\
\hline 2nd & $118.3 \pm 6.3$ & $0.6 \pm 0.3$ & $46.6 \pm 2.4$ & - & $34.7 \pm 7.3$ & $52.3 \pm 0.9$ & $201.4 \pm 51.4$ & $21.1 \pm 3.7$ & $6.6 \pm 2.2$ \\
\hline $3 r d$ & $117.9 \pm 6.0$ & $0.4 \pm 0.3$ & $46.5 \pm 2.3$ & - & $33.1 \pm 6.7$ & $48.6 \pm 1.2$ & $198.4 \pm 58.0$ & $19.1 \pm 4.3$ & $6.0 \pm 2.0$ \\
\hline 4th & $117.9 \pm 6.0$ & $0.07 \pm 0.3$ & $46.5 \pm 2.3$ & - & $29.9 \pm 0.4$ & $48.5 \pm 1.2$ & $216.3 \pm 40.6$ & $21.3 \pm 4.8$ & $5.9 \pm 1.9$ \\
\hline 5 th & $117.9 \pm 6.0$ & $0.07 \pm 0.3$ & $46.5 \pm 2.3$ & - & $35.0 \pm 6.8$ & $48.2 \pm 1.4$ & $210.6 \pm 47.0$ & $22.0 \pm 4.1$ & $6.3 \pm 2.3$ \\
\hline \multicolumn{10}{|l|}{ OGg } \\
\hline $1 \mathrm{st}$ & $87.8 \pm 6.7$ & $-34.1 \pm 4.9$ & $34.4 \pm 2.6$ & $12.4 \pm 3.2$ & $27.3 \pm 3.1$ & $54.2 \pm 2.4$ & $109.9 \pm 21.6$ & $27.7 \pm 8.1$ & $21.9 \pm 4.7$ \\
\hline 2nd & $82.8 \pm 5.6$ & $-37.7 \pm 3.9$ & $32.4 \pm 2.3$ & $15.4 \pm 3.3$ & $44.5 \pm 7.6$ & $54.3 \pm 1.6$ & $88.1 \pm 20.2$ & $27.6 \pm 7.0$ & $25.5 \pm 5.0$ \\
\hline 3rd & $79.6 \pm 5.1$ & $-41.0 \pm 2.5$ & $31.1 \pm 2.1$ & $18.4 \pm 3.3$ & $30.8 \pm 3.6$ & $52.9 \pm 1.8$ & $96.1 \pm 20.2$ & $30.0 \pm 6.3$ & $29.1 \pm 5.3$ \\
\hline 4th & $77.7 \pm 4.6$ & $-42.6 \pm 3.1$ & $30.4 \pm 1.9$ & $21.3 \pm 3.3$ & $34.4 \pm 4.8$ & $51.1 \pm 1.7$ & $110.0 \pm 21.2$ & $29.1 \pm 6.8$ & $27.9 \pm 5.0$ \\
\hline 5 th & $76.0 \pm 4.3$ & $-44.1 \pm 3.1$ & $29.7 \pm 1.8$ & $24.4 \pm 3.3$ & $30.6 \pm 4.0$ & $51.0 \pm 1.8$ & $144.5 \pm 29.2$ & $29.1 \pm 5.9$ & $25.4 \pm 4.6$ \\
\hline
\end{tabular}

Data are reported as mean \pm SEM. $\mathrm{BMI}=$ body mass index; TAS = time after surgery; $\mathrm{PTHi}=$ parathyroid hormone; $25-\mathrm{OH}-\mathrm{D}=25-\mathrm{hydroxyvitamin}$ D; IGF-I = insulin-like growth factor-I; Oc = osteocalcin; DPD = deoxypyridinoline/creatinine.

${ }^{*} \mathrm{P}<0.001$ for $\mathrm{CG}$ vs OG; ${ }^{* \star} \mathrm{P}<0.001$ for $\mathrm{OG}$ vs $\mathrm{OGg} ;{ }^{* \star *} \mathrm{P}<0.01$ for $\mathrm{CG}$ vs $\mathrm{OGg}$; ${ }^{* \star *} \mathrm{P}<0.001$ for $\mathrm{CG}$ vs $\mathrm{OGg} ;{ }^{+} \mathrm{P}<0.05$ for $\mathrm{CG}$ vs $\mathrm{OGg}$; ${ }^{++} \mathrm{P}<$ 0.01 for $O G$ vs OGg; ${ }^{++} P<0.01$ for $C G$ vs $O G$ (ANOVA followed by the multiple comparisons Tukey test for the numerical variables with normal distribution). ${ }^{\#} \mathrm{P}<0.01$ for $\mathrm{BMI}$ variation in $\mathrm{OGg}$ (paired Student $t$-test). 
collection $\mathrm{CG}=255.6 \pm 52.1$ and $\mathrm{OG}=$ $184.9 \pm 35.6 \mathrm{ng} / \mathrm{mL}$ ). In contrast, the circulating IGF-I levels of OGg were significantly lower than those of the other two groups (first collection: $\mathrm{OGg}=109.9 \pm 21.6 \mathrm{ng} / \mathrm{mL}$; Table 2).

The osteocalcin levels of the control group were similar to those of the group submitted to bariatric surgery but significantly higher than those of the obese group (Table 2). Urinary deoxypyridinoline excretion was significantly higher in the group submitted to bariatric surgery than in the other two groups at all five evaluations performed (Table 2). There were no significant differ-

Figure 1. Bone mineral density (BMD) at L1-L4 (A) and in the femoral neck (B) of the control group (CG) and obese group (OG) submitted to bariatric surgery (OGg), and in the distal $1 / 3$ of the radius $(C)$ in $C G$, OGg and OG during the longitudinal study (first and second evaluations). $A$, ${ }^{*} \mathrm{P}<0.0001$ between the first and second evaluations of OGg. $B,{ }^{* *} \mathrm{P}<0.0008$ between the first and second evaluations of OGg. $C,{ }^{* \star *} \mathrm{P}<0.002$ between the first and second evaluations of $\mathrm{OGg}$ (paired Student $t$-test for the data of the same group and unpaired $t$-test for the data of different groups; ANOVA followed by the multiple comparisons Tukey test for the numerical variables with normal distribution was used for the assessment of the three groups).

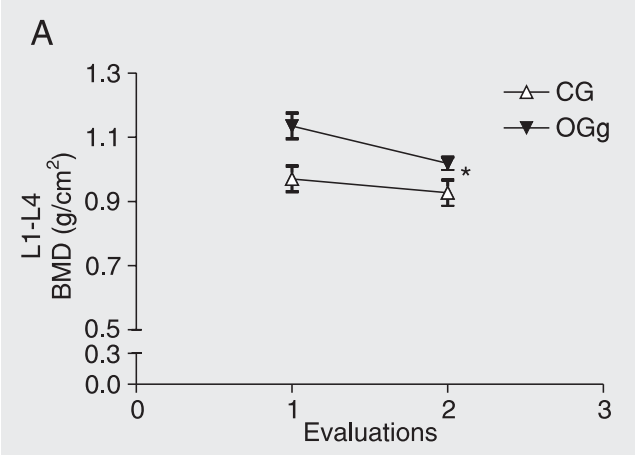

B
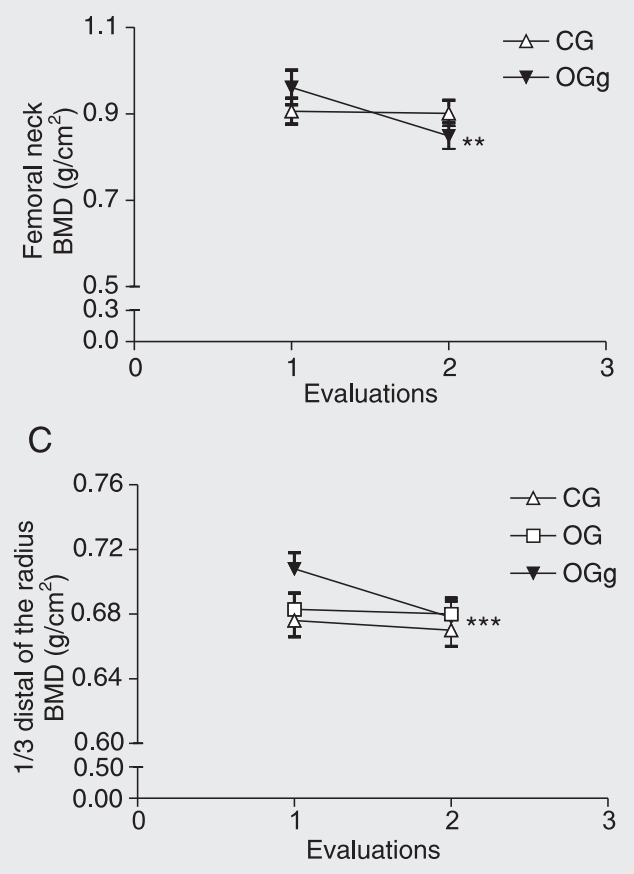

ences in urinary creatinine levels between groups (i.e., 1st evaluation: $\mathrm{CG}=14.3 \pm 0.3 \mathrm{vs}$ $\mathrm{OG}=17.2 \pm 2.6 v s \mathrm{OGg}=12.3 \pm 1.7 \mathrm{mmol} / \mathrm{L}$; 5th evaluation: $\mathrm{CG}=14.6 \pm 0.3$ vs $\mathrm{OG}=17.1$ \pm 2.5 vs $\mathrm{OGg}=12.7 \pm 1.9 \mathrm{mmol} / \mathrm{L}$ ).

While the individuals in the control and obese groups showed stability of BMD throughout the period of evaluation, the individuals submitted to gastroplasty showed a reduction in BMD at all sites evaluated (forearm - first evaluation: $\mathrm{CG}=0.676 \pm$ $0.01 v s \mathrm{OG}=0.683 \pm 0.01$ vs $\mathrm{OGg}=0.708 \pm$ $0.01 \mathrm{~g} / \mathrm{cm}^{2}$. Second evaluation: $\mathrm{CG}=0.670$ $\pm 0.01 v s \mathrm{OG}=0.680 \pm 0.01$ vs $\mathrm{OGg}=0.678$ $\left.\pm 0.01 \mathrm{~g} / \mathrm{cm}^{2}\right)$. Femoral neck - first evaluation: $\mathrm{CG}=0.906 \pm 0.01 v s \mathrm{OGg}=0.961 \pm$ $0.04 \mathrm{~g} / \mathrm{cm}^{2}$. Second evaluation: $\mathrm{CG}=0.901$ \pm 0.03 vs $\mathrm{OGg}=0.849 \pm 0.03 \mathrm{~g} / \mathrm{cm}^{2} . \mathrm{L} 1-\mathrm{L} 4$ - first evaluation: $\mathrm{CG}=0.970 \pm 0.04$ vs $\mathrm{OGg}$ $=1.135 \pm 0.04 \mathrm{~g} / \mathrm{cm}^{2}$. Second evaluation: $\mathrm{CG}=0.927 \pm 0.04$ vs $\mathrm{OGg}=1.018 \pm 0.02 \mathrm{~g} /$ $\mathrm{cm}^{2}$; Figure 1).

\section{Discussion}

Body weight is an important determinant of bone mass in human beings, with low weight being actually considered to be a risk factor for osteoporosis (8-11). Several lines of evidence indicate that both the content of muscle tissue and the content of adipose tissue are positively correlated with BMD (9). Over the last few years, in view of the increasingly popular radical treatment for morbid obesity by gastric reduction surgery, there has been great interest in determining the impact of marked weight loss on bone mass $(3,4)$. In the present study, we evaluated the bone mass of morbidly obese individuals about 9 months after surgery and compared the results obtained to those observed in a group of individuals of normal weight and in a group of obese subjects whose weight was similar to that of the operated group before surgery. A subgroup of these patients was followed up for one year at 3-month intervals. The results showed 
that, on a short-term basis ( 9 months), the patients submitted to gastroplasty presented not only a significant weight loss, but also hormonal changes such as reduction of IGFI, which may have been responsible for the induction of bone mass loss. Indeed, the increase in deoxypyridinoline detected during this period indicated increased bone resorption activity. On a medium-term basis, i.e., 12 to 24 months after gastroplasty, the patients showed a less marked weight loss but maintained a pattern of elevated bone resorption. Although the loss of bone mass is more marked at sites supporting a greater weight load, it also occurs in the forearm, indicating that the reduction of BMD involves not only mechanical factors but also hormonal factors.

A recent study on morbidly obese patients submitted to bariatric surgery reported results that were similar to ours in several aspects (12). It was observed that by about 9 months after surgery the patients showed a significant fall in hip bone mass. In contrast to our results, Coates et al. (12) did not observe a significant loss of forearm BMD in their patients. The group evaluated in that study was heterogeneous, including pre- and postmenopausal women and men, whereas in our study we evaluated only premenopausal women. This factor may have been responsible, at least in part, for the differences observed. An additional aspect of our study is that we also evaluated individuals of normal weight. Thus, it was clearly demonstrated that, while normal and obese individuals maintain a normal bone mass, obese individuals submitted to bariatric surgery show a loss of bone mass.

In agreement with the loss of bone mass manifested, the individuals submitted to gastroplasty showed a significant increase in urinary deoxypyridinoline, which indicated an increase in bone resorption activity. In parallel, the elevation in serum osteocalcin levels was discrete and nonsignificant throughout the study, suggesting that the increase in bone formation activity was not of the same magnitude as the increase in bone resorption. It is also interesting to observe that non-operated obese individuals had significantly lower osteocalcin levels than normal individuals. Similar data were also observed by Hyldstrup et al. (13), suggesting that the bone remodeling rate is reduced in obese subjects. This may be a mechanism protecting against the loss of bone mass in the obese group in view of the fact that in other situations in which there is a greater protection against the loss of bone mass, as is the case for the black race, the remodeling rate is lower $(14,15)$.

The cause of the bone mass loss in obese subjects after weight loss has not been fully elucidated. Jensen et al. (9) attributed this occurrence to a physiological adaptation, a hypothesis based on the observation that the fall in bone mass occurs only during weight loss and that during the maintenance of body mass there is stabilization of bone mass. However, in 2001 the same group (16) suggested that hormonal factors and nutritional changes may also be involved in the loss of bone mass during weight loss. Our results show that patients submitted to bariatric surgery present some alterations. The first is a reduction of urinary calcium loss and the second is elevation of serum 25-hydroxyvitamin D levels. The reduction in urinary calcium loss has been observed in other studies $(9,12)$ and is probably due to limited absorption and/or ingestion of calcium. In favor of this hypothesis, we observed that calciuria tended to normalize one year after surgery. Although an increase in 25-hydroxyvitamin D levels was not observed in some studies, this increase was detected in reports by other investigators (17-19) who attributed the increased levels of this steroid to release from adipose tissue. However, it is unlikely that the changes in mineral metabolism observed are the main factors responsible for changes in bone mass in patients submitted to gastroplasty, especially because 
the serum levels of PTH, the main hormone regulating calcium metabolism, remained normal and similar in the three study groups.

Several systemic factors may be involved in the increased bone resorption after bariatric surgery. Leptin, a hormone primarily associated with the control of energy conservation in humans, is a hormone with multiple functions, which also affects the regulation of bone remodeling (20-22). Recent studies evaluating the influence of leptin on bone mass in human beings by the determination of serum leptin levels and by measurement of BMD have shown contradictory results. This suggests that this is not an adequate model for the evaluation of the physiological role of leptin in skeletal tissue $(21,23)$. Thus, in the present study we did not evaluate the serum leptin levels of our patients. We determined the levels of IGF-I that have a positive influence on osteogenesis. We observed a significant and sustained fall in the serum levels of this growth factor in patients submitted to bariatric surgery. The interpretation of this result is complex in view of the fact that more importance has been attributed to the influence of IGF-I produced in the osseous microenvironment on the stimulation of osteogenesis than to systemic IGF-I (24). However, Yakar and Rosen (25), in an experimental study on transgenic rats with hepatic IGF-I and acidlabile subunit deficiency, demonstrated that systemic IGF-I is also important for the development and acquisition of bone mass. A recent study on Japanese women aged 46 to 88 years demonstrated a positive correlation between IGF-I and lumbar spine and forearm BMD (26). Similar results were observed in previous studies (27). The important role of systemic IGF-I on bone mass, was also highlighted in a recent study, where we showed that low IGF-I in children in the early stage of chronic cholestatic liver disorder, is associated with impairment of bone mass development (28). The absence of an increase in osteocalcin in the operated patients of the present study may reflect the reduction of osteoblast-stimulating factors such as insulin and IGF-I.

The present study calls attention to the fact that individuals submitted to gastroplasty experience a significant reduction of bone mass which starts and is maintained one year after surgery, being mainly due to increased bone resorption. The fall in BMD occurs even at sites that do not support a weight load, such as the forearm, suggesting that systemic factors are involved in addition to mechanical ones. It is possible that the reduction in IGF-I levels contributes to this occurrence.

\section{Acknowledgments}

The authors are grateful to Sebastião Lázaro Brandão Filho and Nadia Bittar Garcia for laboratory assistance and Massako Sakai Kodama and Rita de Cássia C.V. Barbosa for the bone density exams.

\section{References}

1. Majid N. The obesity epidemic: lessons from the war on smoking. Mo Med 2005; 102: 550-554.

2. NIH conference. Gastrointestinal surgery for severe obesity. Consensus Development Conference Panel. Ann Intern Med 1991; 115: 956-961.

3. Hla MM, Davis JW, Ross PD, Wasnich RD, Yates AJ, Ravn P, et al. A multicenter study of the influence of fat and lean mass on bone mineral content: evidence for differences in their relative influence at major fracture sites. Early Postmenopausal Intervention Cohort (EPIC) Study Group. Am J Clin Nutr 1996; 64: 354-360.
4. Mazess RB, Barden HS, Drinka PJ, Bauwens SF, Orwoll ES, Bell $\mathrm{NH}$. Influence of age and body weight on spine and femur bone mineral density in U.S. white men. J Bone Miner Res 1990; 5: 645652.

5. Karmali S, Shaffer E. The battle against the obesity epidemic: is bariatric surgery the perfect weapon? Clin Invest Med 2005; 28 : 147-156.

6. Buchwald H, Williams SE. Bariatric surgery worldwide 2003. Obes Surg 2004; 14: 1157-1164.

7. Glüer CC, Blake G, Lu Y, Blunt BA, Jergas M, Genant HK. Accurate 
assessment of precision errors: how to measure the reproducibility of bone densitometry techniques. Osteoporos Int 1995; 5: 262-270.

8. Reinehr T, de Sousa G, Roth CL, Andler W. Androgens before and after weight loss in obese children. J Clin Endocrinol Metab 2005; 90: 5588-5595.

9. Jensen LB, Quaade F, Sorensen OH. Bone loss accompanying voluntary weight loss in obese humans. J Bone Miner Res 1994; 9: 459-463.

10. North American Menopause Society. Management of postmenopausal osteoporosis: position statement of the North American Menopause Society. Menopause 2002; 9: 84-101.

11. Reid IR. Relationships among body mass, its components, and bone. Bone 2002; 31: 547-555.

12. Coates PS, Fernstrom JD, Fernstrom MH, Schauer PR, Greenspan SL. Gastric bypass surgery for morbid obesity leads to an increase in bone turnover and a decrease in bone mass. $J$ Clin Endocrinol Metab 2004; 89: 1061-1065.

13. Hyldstrup L, Andersen T, McNair P, Breum L, Transbol I. Bone metabolism in obesity: changes related to severe overweight and dietary weight reduction. Acta Endocrinol 1993; 129: 393-398.

14. Weinstein RS, Bell NH. Diminished rates of bone formation in normal black adults. N Engl J Med 1988; 319: 1698-1701.

15. Finkelstein JS, Lee ML, Sowers M, Ettinger B, Neer RM, Kelsey JL, et al. Ethnic variation in bone density in premenopausal and early perimenopausal women: effects of anthropometric and lifestyle factors. J Clin Endocrinol Metab 2002; 87: 3057-3067.

16. Jensen LB, Kollerup G, Quaade F, Sorensen OH. Bone mineral changes in obese women during a moderate weight loss with and without calcium supplementation. J Bone Miner Res 2001; 16: 141147.

17. Rosenstreich SJ, Rich C, Volwiler W. Deposition in and release of vitamin D3 from body fat: evidence for a storage site in the rat. J Clin Invest 1971; 50: 679-687.

18. Rickers $\mathrm{H}$, Balslev I, Foltved H, Rodbro P. Bone mineral content before and after intestinal bypass operation in obese patients. Acta Med Scand 1981; 209: 203-207.

19. Bell NH, Epstein S, Greene A, Shary J, Oexmann MJ, Shaw S.
Evidence for alteration of the vitamin D-endocrine system in obese subjects. J Clin Invest 1985; 76: 370-373.

20. Cornish J, Callon KE, Bava U, Lin QX, Naot D, Hill BL, et al. The direct actions of leptin on bone cells increase bone strength in vivo an explanation of low fracture rates in obesity. Bone 2001; 28 (Suppl): 88S.

21. Yamauchi M, Sugimoto T, Yamaguchi T, Nakaoka D, Kanzawa M, Yano S, et al. Plasma leptin concentrations are associated with bone mineral density and the presence of vertebral fractures in postmenopausal women. Clin Endocrinol 2001; 55: 341-347.

22. Cohen MM Jr. Role of leptin in regulating appetite, neuroendocrine function, and bone remodeling. Am J Med Genet A 2006; 140: 515524.

23. Yilmazi M, Keles I, Aydin G, Orkun S, Bayram M, Sevinc FC, et al. Plasma leptin concentrations in postmenopausal women with osteoporosis. Endocr Res 2005; 31: 133-138.

24. Sjogren K, Jansson JO, Isaksson OG, Ohlsson C. A model for tissue-specific inducible insulin-like growth factor-I (IGF-I) inactivation to determine the physiological role of liver-derived IGF-I. Endocrine 2002; 19: 249-256.

25. Yakar S, Rosen CJ. From mouse to man: redefining the role of insulin-like growth factor-I in the acquisition of bone mass. Exp Biol Med 2003; 228: 245-252.

26. Yamaguchi T, Kanatani M, Yamauchi M, Kaji H, Sugishita T, Baylink DJ, et al. Serum levels of insulin-like growth factor (IGF); IGFbinding proteins $-3,-4$, and -5 ; and their relationships to bone mineral density and the risk of vertebral fractures in postmenopausal women. Calcif Tissue Int 2006; 78: 18-24.

27. Kim JG, Shin CS, Choi YM, Moon SY, Kim SY, Lee JY. The relationship among circulating insulin-like growth factor components, biochemical markers of bone turnover and bone mineral density in postmenopausal women under the age of 60. Clin Endocrinol 1999; 51: 301-307.

28. Taveira ATA, Fernandes MIM, Galvão LC, Sawamura R, Vieira EM, Paula FJA. Impairment of bone mass development in children with chronic cholestatic disease. Clin Endocrinol 2007 (in press). 